\title{
Summary of Slope Ecological Protection Technology
}

\begin{abstract}
Hua Guo*
Weinan Branch Office, Shaanxi Provincial Land Engineering Construction Group, Weinan 714000, Shaanxi Province, China

*Corresponding author: Hua Guo, 865702953@qq.com

Abstract: It is an important issue for sustainable economic development to give consideration to both project development and environmental protection. At present, we must confront and seriously deal with the problems of rational utilization of resources, protection of the environment and beautification of the environment in engineering construction. This paper describes a variety of slope plant protection technology, which can not only play a good role in slope protection, but also improve the engineering environment and reflect the beauty of natural environment, so as to provide reference for slope ecological protection.
\end{abstract}

Keywords: Slope; Ecological protection; Theory; Technology

Publication date: July 2021; Online publication: July 31, 2021

\section{Introduction}

Highway, railway, water conservancy and other engineering construction are closely related to the natural environment. The project has large scale, many projects and wide coverage. A large number of exposed earth rock slopes formed by the earth rock filling and excavation project destroy the existing vegetation and have a great impact on the local ecological environment. In the past, simple engineering protection was usually used, such as mortar (dry) rubble, shotcrete and anchor protection, etc. These engineering measures all led to the original vegetation damage, soil erosion, landslide, landslide and so on slope instability and a series of ecological environment and engineering problems ${ }^{[1]}$. Over the past decade, people have developed a variety of new slope ecological protection technologies, which can not only play a good role in slope protection, but also improve the engineering environment and reflect the beauty of the natural environment. Together with the traditional slope engineering protection measures, the slope engineering plant protection system has been widely used in all kinds of rock slopes and soil slopes.

\section{Principle and function of slope ecological protection}

Slope ecological protection refers to the use of green vegetation or green plants with auxiliary materials instead of traditional stone and other engineering measures for slope protection ${ }^{[2]}$. In this way, plant roots and soil particles are bonded to form a large area of aggregates, which can increase the anti-erosion ability of soil, effectively stabilize soil, protect soil and conserve water, and reduce water and soil loss. Moreover, the construction speed is fast, the investment per unit area is small, and the effect is fast, so that the local environment of the slope area can be quickly improved.

\section{Three commonly used slope ecological protection technology}

\subsection{Slope protection by spraying and sowing of foreign soil}

The slope protection by spraying and sowing of foreign soil is a kind of slope plant protection measure, in 
which the soil or substrate (foreign soil) and seeds with a certain thickness suitable for plant growth are mechanically sprayed and filled (or manually laid) by hanging nets on the slope surface. The technology is suitable for soil slope with slope ratio less than 1:1 and height less than two meters, and road slope with height less than 4 meters or more than four meters and engineering measures. It is characterized by low cost, simple construction and fast speed. Generally, greening protection function can be initially formed from January to February, and has wide adaptability. As the soil can be mixed by machinery, it is easy to implement, so the degree of mechanization of construction is required to be higher. However, it has obvious advantages over mortar rubble and hanging net shotcrete in terms of efficiency and cost, and has obvious greening protection effect, low maintenance requirements and strong adaptability to plant growth. At present, the technology has been widely used in highway slope protection.

\subsection{Slope protection by spraying mixed vegetation}

Spray mixed planting greening slope protection is a kind of construction technology of using foreign soil mixed with adhesive and anchor rod to reinforce wire mesh on stable rock slope, using special jet machine to spray evenly mixed planting base material on the slope, plants rely on "base material" to grow and develop, forming plant slope protection. It has the dual functions of slope protection and vegetation restoration, and can replace the traditional spray anchor protection Stone masonry slope protection and other construction technologies. The planting base material used in this technology is composed of soil, mixed grass and shrub seeds, organic matter, fertilizer, bonding material, water retaining material, stabilizer, $\mathrm{pH}$ release agent, water, etc. the proportion of the mixing material is the key factor of the technology. It can be used on the rock slope with a slope steeper than 1:0.75, which can effectively increase the slope protection strength and the ability to resist rain erosion, and keep enough porosity and fertility to ensure plant growth. This technology realizes the perfect combination of slope protection and landscape greening, which is a breakthrough in environmental protection and land greening engineering. It has been widely used in highway, railway, water conservancy and other rock slope greening protection projects.

\subsection{Honeycomb grid grass planting for slope protection}

Honeycomb grid grass slope protection is similar to dry rubble slope protection technology. It is a slope protection measure that after paving regular hexagonal concrete frame bricks on the finished slope surface to form honeycomb grid, planting soil is paved in the grid, and then grass is planted or planted in the brick frame. Before the construction of this technology, the key is to do a good job in slope dressing to prevent the grid laying cracking and collapse caused by the uneven slope. At the same time, it is necessary to set up a drainage system. Generally, the transverse spacing of slope drainage ditch is $40 \sim 50 \mathrm{~cm}$. The grid used in this technology can be mass produced in the prefabrication yard, and its stress structure is reasonable. It can effectively disperse the rainwater runoff on the slope, slow down the flow speed, prevent the slope erosion, and protect the growth of turf. This kind of slope protection has the advantages of simple construction, neat appearance, beautiful appearance, double effects of slope protection and greening, and the construction cost is higher than that of mortar gravel skeleton slope protection. This technology is mostly used for the protection of fill slope.

\subsection{Hydraulic spray seeding and grass planting for slope protection}

Hydraulic spray seeding grass slope protection is a new slope plant protection measure implemented in recent years abroad. The method is to mix grass seed, adhesive, fertilizer, soil conditioner, pulp and pigment in the mixing box according to a certain proportion of water, and then spray them to the slope by mechanical pressure to achieve the purpose of grass slope protection. Hydraulic spray seeding is usually carried out in spring and autumn, and construction in rainstorm season should be avoided as far as possible. Slope leveling 
$\rightarrow$ drainage facilities construction $\rightarrow$ spray seeding construction $\rightarrow$ cover non-woven fabric $\rightarrow$ maintenance. This method has the advantages of simple construction, fast speed, wide applicability, low engineering cost, high quality, neat germination rate and good protection effect ${ }^{[3]}$. In general, the plant coverage rate of spray seeding slope can reach more than $70 \%$ after one month, and the function of protection and greening can be formed after two months. At present, hydraulic spray seeding grass slope protection has been widely used in highway, railway, urban construction and other slope protection and greening projects.

\subsection{Geonet planting grass for slope protection}

Geonet planting grass slope protection is a composite slope protection measure which integrates the reinforcement of geonet and plant protection. The geonet used in this technology is a kind of threedimensional net produced by special technology. It is a product of high-density polyethylene extruded into square, rhombic and hexagonal grid shape. It has certain tensile strength, durability, chemical stability, weatherability, corrosion resistance and other properties. After implementation, it not only has the function of reinforcing the slope, but also has the function of strengthening the slope, In the early stage of sowing, it can also ensure that the surface is free from direct rain erosion, keep the soil to help grass seed germination, protect young grass growth, easy to fix the vegetation roots on the slope, gradually make the slope covered by plants, make the vegetation and triangular network form a whole, and then play the role of slope reinforcement together. It is necessary to pay attention to the selection of grass species, the specification of geonet and the treatment of slope foundation surface. At present, geonet planting grass slope protection is mainly used in highway and dam slope protection engineering.

\section{Problems and solutions of slope ecological protection technology}

At present, with the popularization and application of different slope plant protection technology in highway, railway, water conservancy and other construction, all kinds of slope plant protection technology have developed into an important means of slope reinforcement, but there are also some difficult problems.

\subsection{Grass degradation is obvious}

In different engineering construction, due to the small investment in slope greening protection, and the large area and partial location of some slopes, the slope lawn is basically in a natural growth state in the case of low investment, low maintenance or no maintenance in the later stage, and it is easy to cause vegetation degradation and death in case of drought, diseases and pests. With the passage of time, if the supply of nutrients and water is not timely, there will be different degrees of vegetation degradation. If the degradation problem cannot be solved in time, it will not only cause a waste of funds, but also fail to achieve the effect of slope protection, and eventually lead to soil erosion, slope collapse and other problems.

\subsection{Selection of plant seed ratio and plant community structure}

Different types of slopes have different requirements on the structure and morphology of plant community, and the selection of vegetation seed ratio is also different ${ }^{[4]}$. In order to restore the excavated slope to the natural state in a short time, it is necessary to determine the proportion of plant seeds, combine with the structural characteristics of the local dominant community, and study and determine the dynamic relationship between the plant proportion and the final formed plant community during spraying and sowing. Only after the investigation and analysis of the above problems, can we correctly guide the construction and ensure the smooth succession of plant growth from artificial greening to original plant community. 


\subsection{Drought is a threat to slope plants}

After rock slope excavation, due to the thick rock layer, good integrity, generally high and steep slope, after the implementation of plant ecological greening, with the extension of time, hot summer and summer, drought in autumn and winter, soil nutrients of vegetation base soil slowly lose, and soil fertility gradually decreases. How to effectively solve the state of no soil, water shortage, fertilizer shortage of slope and the drought and drought faced by slope vegetation The threat of extreme heat is an important factor to determine the final greening effect and ecological benefits of the slope.

\subsection{Maintenance management difficulties}

Ecological slope protection mainly relies on vegetation production to achieve ecological restoration and beautify the environment. Sufficient water and nutrient supply are the key to the survival and growth of plants, especially in high and steep rock slopes, where the soil matrix of vegetation is thin, water shortage and poor nutrient conditions make it difficult for plants to grow. The slope greening measures cannot achieve long-term stable effect. Moreover, in some areas, less rainfall or large seasonal differences also make the natural growth of slope green plants more difficult. Methods to improve the maintenance measures, enhance the effectiveness of maintenance, timely give sufficient water and nutrients during plant growth, is the key factor to ensure the rapid growth of plants and play the role of slope protection.

\section{Conclusion}

At present, hydraulic spray seeding, soil spray seeding and mixed planting are the most typical ecological protection construction technologies, which are widely used. How to implement the concept of sustainable development of slope greening engineering, we need to carry out a series of research and Analysis on the difficult problems in the aspect of slope ecological protection, increase scientific research investment, introduce advanced technology and equipment, and cultivate professional talents, so as to provide a firm foundation for thoroughly solving the sustainable development of slope ecological protection.

\section{Disclosure statement}

The author declares no conflict of interest.

\section{References}

[1] Bai S, 2005, Greening Engineering Technology of Expressway. Beijing: China Agricultural Press.

[2] Li H, Xing L, Hu A, 2004, Application of Ecological Slope Protection Technology in Nanjing Hangzhou Expressway. China Highway, (18): 38-39.

[3] Wang X, 2004, Application of Spray Seeding Technology for Slope Greening. Highway, V.4.

[4] Guo C, 2019, Development Status and Trend of Ecological Protection Technology for Highway Slope. Science and Technology Innovation Guide, 16: 135. 